\title{
Spinocerebellar ataxia type 5
}

INSERM

\section{Source}

INSERM. (1999). Orphanet: an online rare disease and orphan drug data base.

Spinocerebellar ataxia type 5. ORPHA:98766

Spinocerebellar ataxia type 5 (SCA5) is a rare subtype of autosomal dominant cerebellar ataxia type III (ADCA type III; see this term) characterized by the early-onset of cerebellar signs with eye movement abnormalities and a very slow disease progression. 